\title{
4
}

\section{The Use of Task Analysis and User Acceptability Audits in Implementing Information Technology Systems in Schools}

\author{
Phil Wild \\ Education Department, Loughborough University, Loughborough, LE11 3TU, UK.
}

\begin{abstract}
To be effective, new technology must meet the needs of the organisation into which it is installed. These needs may be expressed at different levels in terms of goals, organisational objectives and individual task needs. Any measure of successful implementation must take into account the inter-relation between these factors, rather than treat them individually. If the intended educational benefits are ultimately to be achieved it is imperative that systems adequately meet the business and/or curriculum needs of schools, contribute to effective organisational activity and meet the task and human/social needs of the user.

Research in the industrial and commercial sectors has shown that the success rate of introducing IT systems into organisations could be as low as $20 \%$. This is obviously a worry if such a level of success is transferred to the education sector when the future and careers of so many people is at stake.

This paper summarises work done in trying to develop strategies, derived from evaluation tools developed in the business sector, which can help to measure the organisational needs of schools and contribute to the evaluation of the IT systems through the task analysis and user acceptability audit, which provides data to feed back into implementation to reduce the possibility of failure and rejection by administrators and teachers.
\end{abstract}

Keyword codes: K3.1; K4.3; K6.1

Keywords: Computer Uses in Education; Organisational Impact; Project and People Management

\section{INTRODUCTION}

One of the consequences of the Education Reform Act of 1988 for England and Wales has been to increase the financial and overall management responsibility of individual schools. The new Act also placed a legal requirement on schools to make available additional information to parents, Governors, Local Education Authorities (LEA's) and the Government Department for Education (DfE). The type and nature of information flow has therefore altered. The internal financial management of schools has, at the same time, become the responsibility of the Governors, managed on a day-to-day basis by the Head teacher.

All these changes have accelerated the need for a full IT management system with the functions of a medium size business system, plus other functions unique to the school environment. However, research on the implementation of IT systems into the operation and management of commercial organisations has shown some disturbing statistics on success rates. Although precise levels of IT implementation success are difficult to obtain, partially due to the lack of initially accepted success criteria at the design stage, a range of research results are reasonably consistent in giving a success rate of about $20 \%$, with a 
further $40 \%$ being marginally successful and $40 \%$ being totally written off. Such work has been reported by Eason [1], Plenart [2], the Department of Trade and Industry in the UK [3] and independent research carried out at Loughborough University by Wolfe-Murphy [4] and Ingelby [5]. This wide variety of research sources provides some confidence that the success rates are, in fact, low. Analysis of the research shows that risk of failure is profoundly affected by the following factors:

- Inadequate consideration of organisational and task issues.

- $\quad$ Failure of the supplier to deliver the promised product.

- Mismatch between expectations of user organisation and suppliers provision.

- Inadequate project and commercial management.

- $\quad$ Lack of awareness and experience in user organisations

- Inadequate support during implementation

Successful implementation is characterised by situations where:

- Organisational changes are identified and exploited.

- $\quad$ Gains are easily quantified.

- $\quad$ Requirements are well defined and led by user needs.

- Expectations of the user organisation and suppliers provision are matched.

- There is a sufficient critical mass of users to exploit the potential for enhanced communication.

- Support and training is designed appropriate to user need.

The Audit Commission for England and Wales [6] identified that IT implementation in Local Government suffered many problems because "few authorities have made arrangements in the past to carry out a detailed review of a newly introduced system to ensure that the application met the original specification or that anticipated benefits were actually achieved". They went on to say that "There is little merit in devoting considerable effort to feasibility studies and other evaluation processes if there is no check that the desired objectives have been achieved."

There is little evidence that any of this 'considerable effort to feasibility studies' formed part of the initial implementation of IT in school administration, and historically 'education' has not actively pursued a policy of evaluating educational change. In fact, a compilation of IT development in seven countries carried out by Visscher and Spuck in 1990 [7] came to the conclusion that "the strategy used in the analysis of the school organisation and the design of computer applications was not very professional". Early attempts at IT systems involved the computerisation of specific administrative tasks in isolation, and the systems produced were merely computerised models of the manual system due to the inability of small scale projects to alter organisational structures and practice. This close modelling to the manual systems also ensured user acceptability in the short term due to immediately identified gains and one-one support and training. However, changes to organisational structures must be included as a possible part of an holistic technology based information system, rather than imposing the technology onto present operational systems.

Writers on innovation acceptance theory have also identified problems relating to the personal and organisational aspects of implementing new IT systems. Mackie and Wylie [8], for example, report that "the significant promises of new computer technology ...... are not likely to be realised unless resistance to innovation, and the reasons for it, are recognised and systematic efforts are made to minimise it". There is a further problem that, with a low level of initial awareness, the innovation may have been developed in anticipation of future needs that intended users are not aware of and may not agree with the innovators that a need actually exists. 
These factors can all be addressed as components of the User Acceptability Audit tool, used in association with a properly designed Task Analysis to inform the requirements of the proposed software and organisational structures at an early stage of development.

\section{THE TASK ANALYSIS}

According to Kirwan and Ainsworth [9] a Task Analysis is the name given to any process that identifies the various tasks that must be performed by users when they interact with systems. Shepherd [10] describes the task analysis as "trying to make sense of what people do or what they actually do". The approach used for a specific task analysis can vary according to the task being examined, and Kirwan and Ainsworth list 41 different techniques with detail descriptions of 25 of them. Although many methods are closely linked to the study of timings of tasks, this is not of primary concern when using the task analysis to observe the functions carried out to achieve a result in the early stages of describing the requirements of systems being used to support school management. Obviously the time factor is important when considering the replacement computerised system to reduce the risk of rejection.

A methodology described by Shepherd [10] is the Hierarchical Task Analysis (HTA) which he specifically links to the development of computer systems and the associated human-computer interaction. School management is particularly concerned with using information generated by the administration system to support the decision-taking process which ultimately affects the learning environment of the school. The HTA starts by looking at the 'goals',. which in the school would relate to the types of decisions which need to be made, and at any stage there might be a series of sub-goals which all contribute to the decision making process. The HTA allows the processes and information flow which contributes to the management decisions to be analysed and charted so that an overall system can be visualised. There will be many instances when a particular piece of information contributes to more then one management decision and such linkage of information can be considered when looking at the way in which a computerised system can minimise direct user manipulation of such information and how indirect users might get access to relevant information.

It is, however, recognised that the objective collection of data on task performance is not easy, and in case of the school administration and management systems this will probably be carried out using a combination of direct observation, questionnaire and discussion with the 'expert' [see, for example, Diaper, 11]. Analysis of the wider aspects of the information flow and administration, such as the needs of individual departments, will also need to be carried out if a computerised system is going to contribute widely to the increased effectiveness and efficiency of the school.

\section{THE USER ACCEPTABILITY AUDIT}

The utility value of the new technologies is largely determined by their acceptability to the user; the user acceptability audit is an attempt to measure the level of acceptance. At the same time, the audit can be used to identify barriers or promoters to the successful implementation of the IT system. This approach is being developed at the Human Sciences and Advanced Technology Research Unit at Loughborough University [12]. The audit focuses on the user, the task, context variables and the technology tool [13] through the consideration of three core concepts:

Usability - the extent to which systems match user characteristics and the skills for the task concerned.

Functional utility - how well a system fits a set of particular task needs. 
User acceptability - how willing users are to use the system in their own organisation.

The acceptability criteria fall into four further categories of task match, ease of use, user support and perceived consequences, the later being used to assess a range of organisational and job related aspects which are affected by the computer system. [for further discussion see, for example 12,13 and 14].

Each user acceptability audit requires the creation of investigative tools based on these criteria but tailored to be context specific using a combination of objective measures and subjective assessments. The objective measures require an examination of the physical environment, hardware configuration and general performance. Subjective assessments would normally be made using pre-defined questions for a semi-structured interview [15].

\section{APPLICATION}

The task analysis and user acceptability audit can be used in schools to assess the needs of the organisation and help to ensure that any implementation is successful in management and adminstration. Small scale trials of the methodology have been carried out at Loughborough University and the results indicate that, although the systems are not in the failure category, they are in need of attention to ensure long term success. These trials involved both direct users and indirect users of a finance management module of a widely used system; direct users being those who actually operate the system and the indirect users are those in the organisation who use the output from the computer to make management decisions.

The task analysis looked at the financial management module of a widely used system. Data was represented in the form of flow charts, and barriers to the smooth flow and operation of the system were tabulated [16]. Important findings included:

- The flow charting showed that the computer system was virtually a direct mimic of the previous manual systems but required a set sequence of inputs to achieve the rquired function. A manual system is inherently flexible because, for example, the user can always put one ledger on the side to refer to another, or flick from one page or one year to another. This flexibility was completely removed.

- There are both system and organisational problems in the present implementation of the systems. Users identified problems in the area of setting up the budget, ordering, reconciliation, and financial summaries.

- A number of users were re-typing printed information from the system into a spreadsheet in order to 'model' particular scenarios. This should not be necessary for a system properly task oriented towards supporting management decisions.

- The ordering system was very restrictive in its operation.

- Financial printouts were not easy to understand and were not under the control of the users

The task analysis study, although only small scale, complemented findings from the initial attempt at contextualising the user acceptability audit which was trialed in 11 secondary schools. The data was analysed in terms of the user acceptance criteria using simple frequency counts, the intention being to assess the systems success and generate information which would identify specific factors acting as promoters and barriers to successful implementation. It is not possible to include the detail of the questions within this paper [see Wild et al, 13 and Scivier, 15] but the main findings are: 
- Ease of Use: The majority of users were generally satisfied with using the system in their work, but specific problems highlighted were printer paper problems, error handling, output, keying and navigation. Error handling and output were the greatest problem areas. It was reported by the users that corrections to data could not be made once data is confirmed and output had to be changed by hand to ensure the accuracy of information. Errors were recorded manually in a book to try to ensure that printouts could always be altered when required. This obviously raises questions about data being accurate and up-to-date. Physical environment caused problems in nearly $50 \%$ of cases and compliance with the EEC Directive 90/270/1992 would obviously be a growing issue.

- Task Match: A serious area of concern was that data was not accurate, recent or complete, exacerbated by the error handling problem. These problems related to the difficulty in maintaining data input due to general workload caused by system implementation.

- Support: This includes issues of training, userguides and external support services. Over $50 \%$ of users reported problems in learning the system, with some of the problems related directly to the training such as delay in using the system after training, and the trainers lack of knowledge of the direct users tasks. The training was system and technology based rather than user context based. The lack of user and organisational tasks being reflected in the index of the user guides caused further problems when searching for help. The level of resourcing of the external support services was questioned, especially in relation to the planned expansion of the systems.

- Perceived consequences: In a cost-benefit analysis, 3 users assigned an overall rating which indicated that the perceived costs outweighed the benefits of the system. Data across specific aspects of job design, organisational issues and personnel policy indicate that changes in aspects of the direct users job design may particularly increase the risk of system rejection, such as work pace and deadlines and an increase in effort by the direct users to keep up with the system requirements. Better career prospects (the ability to apply for jobs outside education!) and increased power and influence of the direct users were helping to promote the system.

\section{DISCUSSION}

An attempt has been made in these small scale unfunded projects to use evaluation tools developed in the industrial and commercial environment in the context of educational management. The end point of any system must be the way it supports management decisions in both pro-active and re-active situations. The better and up-to-date the data, the more decisions can be pro-active.

The projects have resulted in a series of evaluation questions which differentiate between direct and indirect users and put the criteria of the user acceptability audit into the cor. of the school situation. The task analysis methodology has been found to contribute furth information which complements the data from the user acceptability audit to determine promoters and barriers to the system success.

The data collected allows us to draw some conclusions about the information technology systems examined in the one authority, but it must be realised that such analysis is not usually directly transferable to other organisations. 
- The task analysis demonstrated that in many areas of financial managment, the computer system is being used mainly as an electronic version of the manual paper system, with an inherent lack of flexibility.

- The user acceptability audit highlighted problems which will probably limit long term success, in that the system failed to fully meet task demands, barriers to effective use were identified, there is a risk of inaccuracies in processing and analysing data and risks were compounded by a lack of consideration of some organisational and job design factors.

The Local Education Authority responded positively to the findings of this first attempt at an evaluation methodology for such systems in that they felt that "barriers and promoters has thrown considerable light on the strategy and tactics the LEA needs to adopt to successfully establish the use of computerised information systems in schools" [private communication]. This reinforces the conclusion that the packaged tool based on the user acceptability audit would allow schools to systematically evaluate IT systems supporting their administration and management which would give qualitative and quantitative gains to the school

Recent discussion with teachers has shown some improvement in that the software providers are listening to the users but one teacher involved with using the system succinctly summarised the present situation when he said of the programs "it seems like a series of good ideas which fail at the last hurdle because they don't match the real life situation in the school" [private communication]. This same teacher also uses Dataease and Lotus 1-2-3 to do some jobs "because the main system is too slow", with the need to duplicate data entry. Manuals are still not indexed on tasks or the needs of indirect users and manuals are always a version behind the software. He reports that the system does not save any time due to poor implementation and support. Any system perceived by the users as a poor system cannot be a successful system. It has, however, been found in commercial organisations that there is sometimes a problem in identifying a poor system because "resourceful employees manage to bypass the new system or to keep the old system operating in parallel to carry out tasks made impossible by the new arrangement. The failure of the new system is often not consciously acknowledged in such cases and it may even be proclaimed an 'official' success, even though its full potential is not being realised" [17]. The questions used during a user acceptability audit need to be sensitive to such problems within the context of the organisation.

In 1991, Visscher [18] pointed out that there has been little attempt to assess the effectiveness of computer systems per se, or to evaluate the effectiveness as part of organisations and that "in short, we are lacking substantial data concerning the impact of school administration computerisation". Further development and more extensive testing of the evaluation tools initially contextualised and trialed at Loughborough University is now required to improve the tools sensitivity and range to provide the required data so that future systems can work from a basis of knowledge of what is really required of systems. Individual institutions can then begin to understand the organisational implications and impact of implementing IT systems from the perspective of a range of direct and indirect users.

\section{REFERENCES.}

1. Eason, K.D., Information Technology and Organisational Change, Taylor and Francis, London, 1988.

2. Plenart, G., 'The Basis of a Successful System', Information and Management, 15, 251$254,1988$. 
3. Department of Trade and Industry, Profiting from Office Automation: Office Automation Pilots, DTI, London, 1986.

4. Wolfe-Murphy, V.B., 'The uptake of information Technology by small and medium sized enterprises in Leicestershire' MSc Research Dissertation, Loughborough University, 1988.

5. Ingleby, A., 'Loughborough small businesses and the computerisation process', MSc Research Dissertation, Loughborough University, 1989

6. Audit Commission, 'Preparing an Information Technology Strategy: Making IT Happen', Audit Commission Management Papers, 7, 1990, HMSO, London.

7. Visscher, A.J. and Spuck, D.W., 'Computer Assisted School Administration and Management: The State of the Art in Seven Nations', Journal of Research on Computing in Education, 24, 1, 1991

8. Mackie, R.R. and Wylie, C.D., 'Factors Influencing Acceptance of Computer Based Innovation', in M. Helander (Ed), Handbook of Human-Computer Interaction, NorthHolland, Elsevier.

9. Kirwan, B. and Ainsworth, L.K. (Ed), A Guide to Task Analysis, Taylor \& Francis, London, 1992.

10. Shepherd, A., Analysis and Training in information technology tasks, in Diaper, D. (Ed), Task Analysis for Human-Computer Interaction, Elliss Horwood Ltd., 1989.

11. Diaper, D., Task Observation for Human-Computer Interaction, in Diaper, D. (Ed), Task Analysis for Human-Computer Interaction, Elliss Horwood Ltd., 1989.

12. Richardson, S., 'Operationalising usability and acceptability - a methodological review' in Wilson, J.R., Corlett, E.N. and Manenica, I. (Ed) New Methods in Applied Ergonomics, Taylor \& Francis, 1987.

13. Wild, P., Scivier, J.E. and Richardson, S.J. 'Evaluating Information Technologysupported Local Management of Schools: The User Acceptability Audit', Educational Management and Administration, 20, 1, 1992.

14. Shackel, B. and Richardson, S.J. (Eds), Human Factors for Informatics Usability, Cambridge University Press, 1991.

15. Scivier, J. A User Acceptability Evaluation of a Computerised Administration System in a Local Education Authorities Secondary Schools, MSc Research Dissertation, Loughborough University, 1990.

16. Mitchell, S. and Wild, P., 'A Task Analysis of a computerised System to Support Administration in Schools', Educational Management and Administration, 21,1,1993.

17. Richardson, S and Otway, H., 'User Acceptance of man-machine systems', ManMachine Systemis, Varse, Italy, 1985.

18. Visscher, A.J., 'School Administration Computing: A Framework for Analysis',Journal of Research on Computing in Education, 24, 1, 1991 